\section{Note}

Distributional data for the terrestrial and aquatic fauna is available via the Evolution and Biodiveristy in the Antarctic (EBA) dataportal (www. eba.aq/), while marine data is available in the SCAR Marine Biodiversity Information Network (SCAR-MarBIN) database (www.scarmarbin. be/).

\section{References}

Convey, P. and Stevens, M.I., 2007: Antarctic biodiversity, Science, 317 1877-1878.

Convey, P., Gibson, J.A. Hellenbrand, C, Hodgson, D. A, Pugh, PJ.A. Smellie, J.L. and Stevens, M.I., 2008: Antarctic terrestrial life challenging the history of the frozen continent? Biological Reviews, 83: 103-117.

Cromer, L., Gibson, J.A.E., Swadling, K.M. and Hodgson, D., 2006: Evidence for a lacustrine faunal refuge in the Larsemann Hills, East Antarctica, during the Last Glacial Maximum, Journal of Biogeography, 33: 1314-1323
Gibson, J.A.E. and Bayly, I.A.E., 2007: New insights into the origins of crustaceans of Antarctic lakes, Antarctic Science, 19: 157-164.

Page, T. and Linse, K., 2002: More evidence of speciation and dispersal across the Antarctic Polar Front through molecular systematics of Southern Ocean Limatula (Bivalvia: Limidae), Polar Biology, 25: $818-826$.

For full references please consult:

www.pages-igbp.org/products/newsletters/ref2009_1.html

\title{
Sea-ice proxies in Antarctic ice cores
}

Regine Röthlisberger and Nerilie Abram

British Antarctic Survey, Cambridge, UK; rro@bas.ac.uk

\section{Chemical parameters routinely analyzed in ice cores hold information on past changes in sea ice extent around Antarctica, providing a long-term perspective on sea ice.}

Sea ice plays a crucial role in the Earth System: Apart from its direct influence on radiative balance via its albedo, it also has a large influence on ocean-atmosphere exchange processes, ocean stratification and atmospheric circulation. Furthermore, sea ice is instrumental in the formation of deepwater masses and thus influences the global thermohaline circulation. Despite its importance, sea ice remains a poorly constrained component in model simulations of past and ongoing climate change. Much of this uncertainty is due to the paucity of information about past sea ice conditions.

Various methods have been applied to derive past sea ice extent. For the most

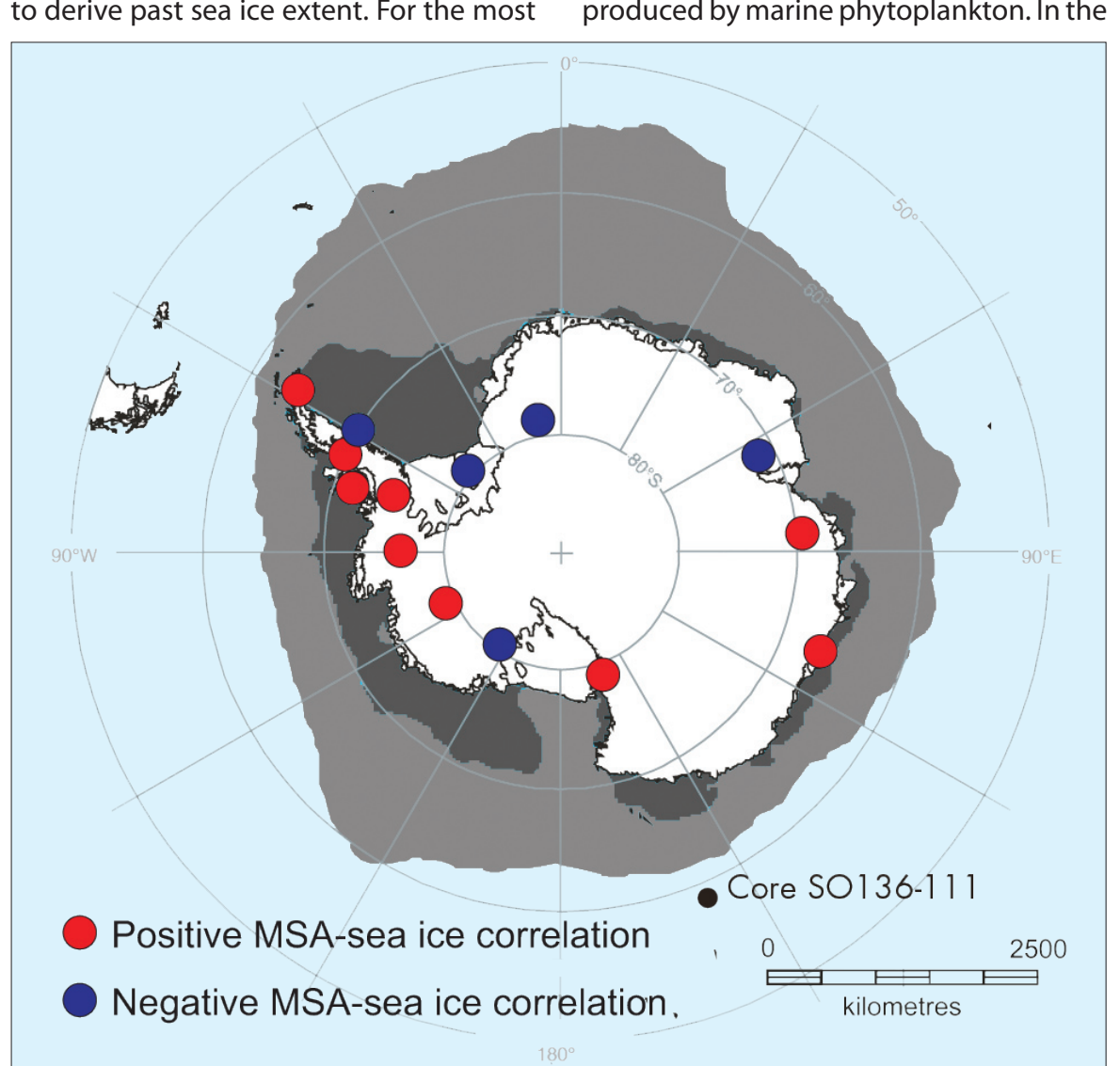

Figure 1: Spatial pattern of the correlation between methanesulfonic acid (MSA) for different coastal Antarctic ice core sites, and the winter maximum sea ice extent for the longitudinal sector considered to be the relevant source (Welch et al., 1993; Sun et al., 2002; Curran et al., 2003; Foster et al., 2006; Abram et al., 2007; Abram, unpublished data). Light and dark gray shading denotes mean winter and summer sea ice extent, respectively.
Southern Ocean, large amounts of DMS are produced by algae in the sea-ice zone (Curran and Jones, 2000). More extensive winter sea ice promotes increased phytoplankton activity during seasonal sea ice melt, and the associated increased release of DMS is reflected by greater amounts of MSA deposited in nearby snow layers.

A pioneering paper by Curran et al. (2003) showed remarkable agreement between the MSA record from Law Dome, a coastal ice dome in East Antarctica, and the satellite-derived sea ice maximum. The MSA record clearly traced the decadal-scale variability found in the satellite record of maximum sea ice extent. Using MSA as a proxy for regional sea ice extent allowed the satellite record to be put into a century-scale context, from which Curran et al. (2003) inferred a $20 \%$ decline in sea ice since 1950 for the $80-140^{\circ} \mathrm{E}$ sector.

Ice core MSA records from a number of other coastal sites also show a positive relationship between MSA and winter sea ice extent (Welch et al., 1993; Foster et al., 2006; Abram, unpublished data), making this a promising proxy for reconstructing regional patterns of sea ice change around Antarctica (Fig. 1). However, there are some limitations in using MSA as a sea ice proxy. Recent work in the Weddell Sea region has found that in some locations the MSA signal in ice cores is more strongly influenced by atmospheric transport strength and direction (Fundel et al., 2006; Abram et al., 2007). There is also evidence that the MSA sea ice proxy is not reliable at some sites around the Ross Sea and Lambert Glacier (Sun et al., 2002), suggesting that embayed coastal locations may not be suitable for sea ice reconstructions, due to geographical constraints on wind-driven transport. Work is currently underway to develop additional MSA records from near-coastal ice core sites, to help define the characteristics of sites where this proxy is reliable, in order to build a regional-scale 


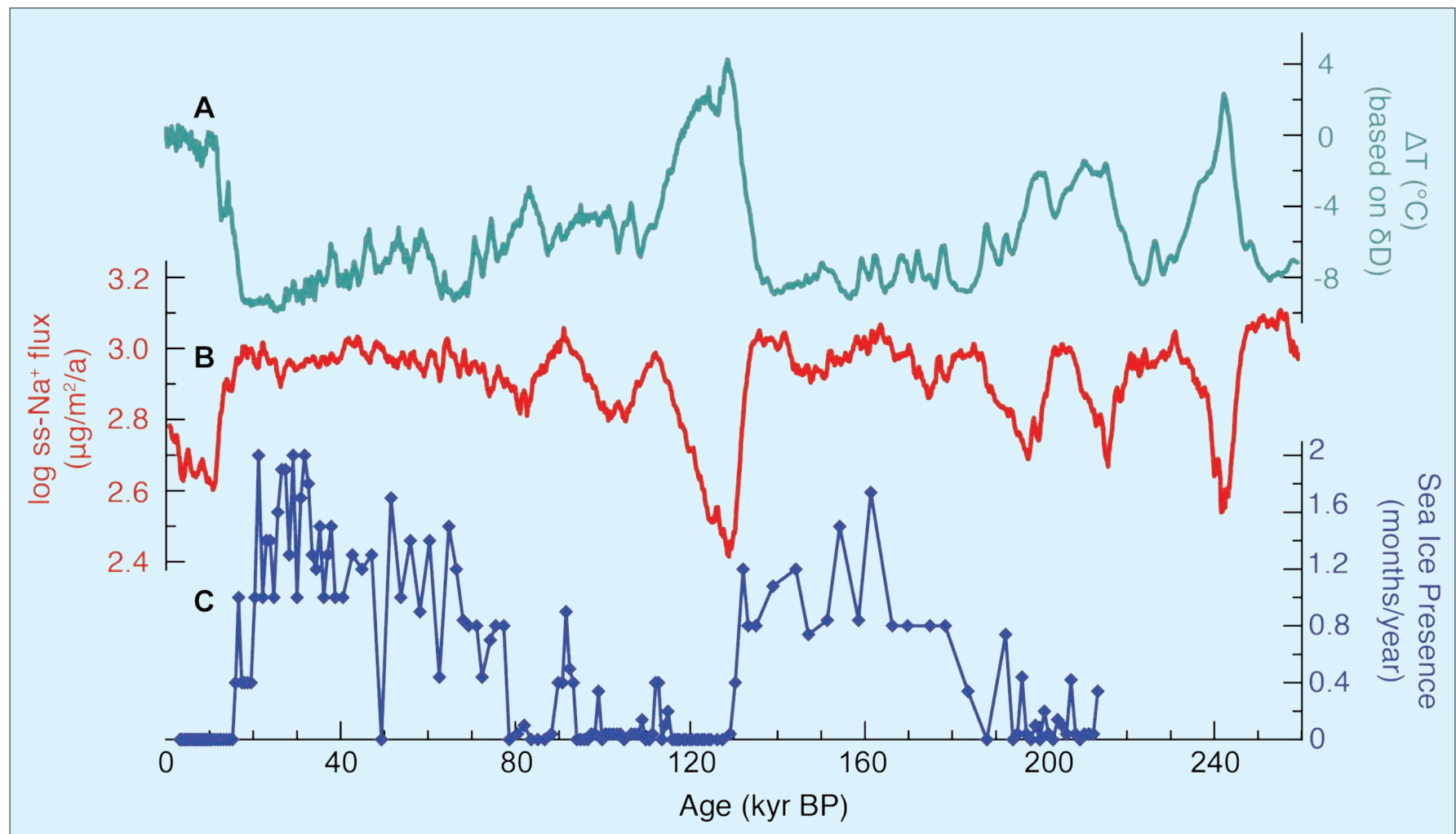

Figure 2: Comparison between ice and marine proxy records of sea ice over the last 2 glacial-interglacial cycles. A) Antarctic temperature anomaly at Dome C relative to modern (Jouzel et al., 2007). B) Sea ice extent proxy (ss Na+ flux) from Dome C (Wolff et al., 2006). C) Sea ice presence derived from diatom assemblages in marine record SO136-111 (Crosta et al., 2004).

synthesis of the history of Antarctic sea ice change (Abram et al., 2008). Conceivably, such reconstructions could be extended over thousands of years. However, on glacial-interglacial timescales, the MSA record in ice cores is likely to be susceptible to changes in the oxidative capacity of the atmosphere (Castebrunet et al., 2006), and to chemical influences on the preservation of MSA, particularly at inland sites with low snow-accumulation rates (Wagnon et al., 1999).

\section{Sea salt}

Sea salt aerosol is generally derived from small air bubbles bursting over open ocean. However, for Antarctica, sea ice surfaces rather than open water have been suggested as the dominant source of sea salt aerosol. Based on this premise, sea salt sodium ( $\left(\mathrm{ss} \mathrm{Na}^{+}\right.$) flux has been used as a qualitative proxy for sea ice extent around Antarctica (Wolff et al., 2003; 2006).

Fresh sea ice is covered by saline brine and it has been shown that blowing snow and small ice crystals growing on these salty surfaces represent effective sources of sea salt aerosol in coastal and inland Antarctica (Rankin et al., 2000; Yang et al., 2008). Two characteristic features of Antarctic sea salt aerosol records support the view that the sea ice surface is a primary source of sea salt aerosol in Antarctica. Firstly, sea salt aerosol concentrations peak in winter, when the open water source is many hundreds of kilometers seaward due to extensive sea ice cover- age. Secondly, sea salt aerosol in Antarctica exhibits marked sulfate depletion, which is incompatible with an open ocean source. Frost flowers and brine on sea ice surfaces, however, are depleted in sulfate due to sodium sulfate being precipitated out while residing on the sea ice surface. Although this strongly supports a link between $\mathrm{ss} \mathrm{Na}^{+}$and sea ice, it is also clear that meteorological conditions responsible for uplift and transport of sea salt aerosol from the sea ice surface to the ice sheet have a large influence on the $s \mathrm{Na}^{+}$flux at any particular site. Nevertheless, average changes in sea ice over relatively long periods (several centuries) and on relatively large spatial scales will leave an imprint on $s s \mathrm{Na}^{+}$flux that stands out against the background of meteorological variability.

The overall pattern of the $s \mathrm{Na}^{+}$record from Dome C, Antarctica, shows general agreement with a sea ice reconstruction based on a marine sediment core from the Indian Ocean sector offshore of Dome C (Fig. 2). Low levels linked to low sea ice extent in the Indian Ocean sector around Antarctica are observed during interglacial periods. A gradual increase in $\mathrm{ssNa}^{+}$flux over the glacial inception and the early part of the glacial period leads to their maximum levels being reached during glacial maxima. However, distinct differences in details of each of these records point toward thresholds in the response of both the sediment core and ice core proxies (Röthlisberger et al., in prep.). A recent study has shown that the response of $s \mathrm{Na}^{+}$flux to a change in sea ice extent, and therefore its use as a sea ice proxy, is greatest for interglacial and moderate glacial climates and decreases with increasing sea ice extent (Röthlisberger et al., 2008), complicating the quantitative interpretation of $s \mathrm{Na}^{+}$. The decrease in sensitivity during glacial periods can be explained by the increasing distance between the aerosol source and the Antarctic ice sheet. Sea salt aerosol concentration is rapidly depleted during transport (Minikin et al., 1994), so that only a small fraction of the sea salt aerosol from the northernmost sea ice areas contributes to the $\mathrm{ss} \mathrm{Na}^{+}$flux at a particular ice core site. Current efforts in sea salt aerosol modeling will improve the quantitative understanding of the ss $\mathrm{Na}^{+}$ice core records.

\section{Conclusions}

Two ice core parameters, MSA and ss $\mathrm{Na}^{+}$, can be linked to sea ice extent around Antarctica. The two proxies operate on different temporal scales: MSA is linked to the winter maximum in sea ice extent and offers high-resolution records over the past few centuries to millennia. Sea salt sodium, on the other hand, only relates to sea ice changes averaged over several centuries but at a qualitative level, ss $\mathrm{Na}+$ records change over several glacial-interglacial cycles. However, for both proxies, site-specific conditions may influence the response to sea ice changes and need to be taken into account on a case-by-case basis. 


\section{Note}

Data include previously published diatomderived sea-ice reconstruction (Crosta et al., 2004; www.sciencedirect.com/science/journal/03778398) and EPICA Dome C ssNa+ flux and D data (NOAA Paleoclimatology website www.ncdc.noaa.gov/paleo/paleo.html).

\section{References}

Abram, N., McConnell, J.R., Thomas, E.R., Mulvaney, R., Aristarain, A.J. 2008: Ice core records of 20th century sea ice decline in the Bellingshausen Sea, Geophysical Research Letters, submitted.

Abram, N., Mulvaney, R., Wolff, E.W., and Mudelsee, M., 2007: Ice core records as sea ice proxies: an evaluation from the Weddell Sea region of Antarctica, Journal Geophysical Research, 112: D15101, doi:15110.11029/12006JD008139.

Röthlisberger, R. et al., 2008: The southern hemisphere at glacial terminations: insights from the Dome C ice core, Climate of the Past:
Open Discussion, 4: 345-356. www.clim-past.net/4/345/2008/ cp-4-345-2008.html

Wolff, E.W. et al., 2006: Southern ocean sea-ice extent, productivity and iron flux over the past eight glacial cycles, Nature, 440: 491-496.

Wolff, E.W., Rankin, A.M., and Röthlisberger, R., 2003: An ice core indicator of Antarctic sea ice production?, Geophysical Research Letters, 30(22): 2158. doi:10.1029/2003GLL18454.

For full references please consult:

www.pages-igbp.org/products/newsletters/ref2009_1.html

\section{Accurate chronology for Antarctic ice cores on orbital}

\section{timescales}

Kenju Kawamura

National Institute of Polar Research, Research Organization of Information and Systems, Tokyo, Japan; kawamura@nipr.ac.jp

An accurate chronology of Dome Fuji and Vostok ice core records, with dating accuracy better than 2 kyr, has been established for the past $\mathbf{4 0 0} \mathrm{kyr}$ and is consistent with the Milankovitch theory for the sequence of 100-kyr climatic cycles.

Deep ice cores from Antarctica have provided key records of past climate, including local temperature, atmospheric greenhouse gases and aerosols (e.g., Petit et al., 1999; Kawamura et al., 2007; Lüthi et al., 2008), over several glacial-interglacial cycles. In particular, the records have revealed a strong correlation between Antarctic temperature and greenhouse gas concentrations. In order to understand further the roles of both orbital and greenhouse gas forcings on climate changes, and to test Milankovitch forcing as the driver for the 100-kyr cycles seen in the ice core proxies, one would need paleoclimate chronologies with accuracy better than $\sim 2 \mathrm{kyr}(\sim 10 \%$ of a precession cycle). A brief review is presented here on recent progress in improving the chronology of Antarctic ice cores for $\sim 80 \mathrm{kyr}$ BP and older, by orbital tuning of the record of oxygen-to-nitrogen concentration ratio $\left(\mathrm{O}_{2} / \mathrm{N}_{2}\right)$ in trapped air with the local summertime insolation (Kawamura et al., 2007; Suwa and Bender, 2008). The implications for our understanding of the mechanisms of glacial cycles is also discussed.

\section{Orbital tuning using $\mathrm{O}_{2} / \mathrm{N}_{2}$}

Dating of the Antarctic deep ice cores involves models of past snow accumulation rates and ice flow (to account for thinning) whose parameters are constrained by depth-age control points with associated uncertainties (typically 2-6 kyr for MIS 5 and older periods). The error of the glaciological chronology may be large (>10 kyr) especially deeper in cores (> 2000 m, e.g., GT4 of Vostok and EDC2 of Dome C chronologies) because the real ice flow and/ or accumulation histories do not follow the models' simple assumptions. Orbital tuning utilizes the known relationship between a measured parameter in the ice and an insolation curve to correct the gla- ciological chronology. Conventional orbital tuning uses global climate proxies, such as atmospheric $\mathrm{CH}_{4}$ or $\delta^{18} \mathrm{O}$ of $\mathrm{O}_{2}$, which are matched to proximal insolation forcing (Dreyfus et al., 2007; Ruddiman and Raymo, 2003). This has brought great improvement over the glaciological chronology (e.g., EDC3 over EDC2 for the Dome C core; Parrenin et al., 2007) but the error is still up to $\sim 6 \mathrm{kyr}$ because the actual phasing between these gas proxies and orbital variations is variable.

New orbital tuning using $\mathrm{O}_{2} / \mathrm{N}_{2}$ has been developed for the Dome Fuji and Vostok cores covering 80-400 kyr BP (Kawamura et al., 2007; Suwa and Bender, 2008) (Fig. 1, A-C). $\mathrm{O}_{2} / \mathrm{N}_{2}$ in these cores is depleted relative to the atmospheric ratio because of physical fractionation during air-bubble formation at $\sim 100 \mathrm{~m}$ depth (Severinghaus and Battle, 2006). The magnitude of this depletion is controlled by the magnitude of snow metamorphism, driven by local summer insolation when the layer was originally at the surface (Bender, 2002).Although the exact mechanisms are currently not well understood, empirical evidence indicates that the $\mathrm{O}_{2} / \mathrm{N}_{2}$ variation is probably phaselocked to the local summer solstice insolation, with negligible climatic influences (Kawamura et al., 2007). The independent Dome Fuji and Vostok $\mathrm{O}_{2} / \mathrm{N}_{2}$ chronologies agree within $1 \mathrm{kyr}$, indicating robustness of the method. The accuracy of the chronology (and thus the assumption of using the solstice insolation as the target) is validated through comparison with several age markers (a volcanic ash layer and $\mathrm{CH}_{4} /$ monsoon abrupt events) whose radiometric ages are accurate to within $\sim 2 \mathrm{kyr}$ for the last $200 \mathrm{kyr}$, and which agree within $2 \mathrm{kyr}$ (Kawamura et al., 2007; Suwa and Bender, 2008; Wang et al., 2008). Suwa and Bender (2008) developed a nearly identical $\mathrm{O}_{2} / \mathrm{N}_{2}$ tuned chronology for the Vostok core (100-
$400 \mathrm{kyr}$ BP), with the addition of new $\mathrm{O}_{2} / \mathrm{N}_{2}$ data and using a slightly different method for the matching. Another local insolation proxy is air content (used for EDC3), although it gives less accurate age control (with an error of $\pm 4 \mathrm{kyr}$ ) partly because of climatic influences (Raynaud et al., 2007).

\section{Climatic implications}

The new chronology permits comparisons between parameters measured in Antarctic ice cores (such as temperature and atmospheric greenhouse gases) and orbital variations, thus providing the possibility to separate the respective contributions to past global climate and sea level changes. The 340-kyr-long Dome Fuji temperature record on the new chronology closely follows boreal summer insolation, possibly with a slight lag behind solstice insolation (Fig. 1D). Thus, the previous arguments of early Antarctic warming following the southern summer insolation to trigger northern deglaciation is not supported by the new chronology. Further, the onset of the last four Antarctic terminations are found to lag behind the minima of insolation by 2-7 kyr, and the entire duration of the warming events fit within the rising phase of June solstice insolation at $65^{\circ} \mathrm{N}$. For the last three glacial inceptions, Antarctica cooled in phase with the decrease in northern summer insolation and before significant decreases seen in $\mathrm{CO}_{2}$ and sea level (Fig. 1, D-F) curves.

The above timings are fully consistent with the view that high northern latitude summer insolation drives the 100-kyr glacial cycles by changing summertime temperature and thus long-term glacial mass balance (Raymo, 1997; Denton et al., 2006), with large amplification by albedo and $\mathrm{CO}_{2}$ feedbacks. This view is supported by the recent analysis of marine sediment data by Bintanja and van de Wal (2008), which 